\title{
The effect of sward perennial ryegrass content and defoliation method on seasonal and total dry matter production
}

\author{
P Creighton $^{1,2}$, E Kennedy ${ }^{1}$, T.J Gilliland ${ }^{3}$, T Boland ${ }^{2}$, M O'Donovan ${ }^{1}$
}

${ }^{1}$ Teagasc Moorepark, Dairy Production Research Centre, Fermoy, Co.Cork, Ireland, ${ }^{2}$ School of Agriculture, Food Science and Veterinary Medicine, University College Dublin, Belfield, Dublin 4, Ireland, ${ }^{3}$ Agri-Food and Biosciences Institute, Crossnacreevy, Co. Down, Ireland

Email: philip.creighton@teagasc.ie

Introduction It is widely accepted that perennial ryegrass dominant swards are more productive. (Frame, 1991). Quantifying the production loss, as sward perennial ryegrass (PRG) content decreases is an important issue for grassland farmers. The evaluation of grass varieties in Ireland uses mechanical defoliation methods and visual ground score estimates of the proportion of PRG in a sward. The objective of this study was to quantify the effect of i) sward PRG content and ii) defoliation method on seasonal and total dry matter (DM) production, as well as the effectiveness of ground cover score estimates in predicting sward PRG content and DM production under actual animal grazing.

Materials and methods Ninety plots were established on free draining, acid brown earth soil with a sandy loam to loam texture in Autumn 2007. The study incorporated three varieties of perennial ryegrass (Lolium perenne L.; PRG) at five different seeding rates $5,7.5,12,20 \& 30 \mathrm{~kg} / \mathrm{ha}$, under 2 defoliation managements; i) a simulated mechanical grazing management (SG) ii) actual animal grazing by dairy cows (AG). Each variety was replicated three times at each seeding rate under the two defoliation managements (3 varieties x 5 seeding rates x 2 defoliation managements, replicated 3 times). The five seeding rates were used to establish swards with approximately $15 \%, 25 \%, 40 \%, 65 \%$ and $100 \%$ PRG content. Plot size was $1.4 \mathrm{~m} \times 5 \mathrm{~m}\left(7 \mathrm{~m}^{2}\right) \mathrm{SG}$, and $2.8 \times 5 \mathrm{~m}\left(14 \mathrm{~m}^{2}\right)$ AG. Plots were grazed nine times during their first full grazing season (February to October 2008). SG plots were harvested using a motor Agria mower (Etesia UK Ltd., Warick, UK). The fresh weight of a $1.2 \times 5 \mathrm{~m}$ strip $(>4 \mathrm{~cm})$ was recorded and a sub-sample $(100 \mathrm{~g})$ dried at $80^{\circ} \mathrm{C}$ for $16 \mathrm{~h}$ to determine dry matter. Herbage yield ( $\mathrm{kg} \mathrm{DM} / \mathrm{ha}$ ) was then calculated. The herbage yield for the AG plots was determined prior to each grazing by cutting a $0.25 \mathrm{~m}^{2}$ sample $(>4 \mathrm{~cm})$ using a 0.5 x $0.5 \mathrm{~m}$ quadrat and Gardena grass shears $(\mathrm{Gardena}, \mathrm{GmbH}$, Ulm Germany), with dry matter determined as described above. Tiller density was assessed in Autumn '08. Three turves $(10 \mathrm{~cm} \times 10 \mathrm{~cm})$ were cut from each plot and dissected. From this, PRG tiller density and total tiller density $/ \mathrm{m}^{2}$ was calculated. All plots were ground cover scored (score 1- 5) based on the proportion of PRG present in the sward. SG plots received $350 \mathrm{~kg}$ nitrogen $(\mathrm{N}) /$ ha over the grazing season, with $A G$ plots receiving $250 \mathrm{~kg} / \mathrm{N} / \mathrm{ha}$, the difference accounting for the nitrogen recycling which would occur on the AG plots. All dung paths were removed from the AG plots after grazing. Data was analysed using PROC GLM in SAS.

Results Sward PRG proportion had no significant effect on PRG or total tiller density. Defoliation method approached significance $(\mathrm{P}<0.07)$ for $\mathrm{PRG}$ tillers $/ \mathrm{m}^{2}$ but had no effect on total tiller density. As sward PRG proportion increased, spring, summer and total dry matter yield increased significantly $(\mathrm{P}<0.001)$. Defoliation method also had a significant effect $(\mathrm{P}<0.001)$ on Spring, Summer and total dry matter yields, with AG having higher yields. There was a significant interaction $(\mathrm{P}<0.02)$ between sward $\mathrm{PRG}$ proportion and defoliation method in Spring, with AG swards consistently having a higher yield across all PRG proportions. Sward PRG proportion had a significant effect on ground score, increasing for $15 \%, 25 \%$ and $40 \%$ swards, with no difference between $65 \%$ and $100 \%$ swards.

Table 1 Effect of sward perennial ryegrass content and defoliation method on tiller density, DM production and ground score (Year 1)

\begin{tabular}{|c|c|c|c|c|c|c|c|c|c|c|c|}
\hline Sward PRG proportion & $15 \%$ & $25 \%$ & $40 \%$ & $65 \%$ & $100 \%$ & Sig. & SG & $A G$ & Sig. & SED & Inter \\
\hline Spr. DM prod (kg/ha) & 364 & 447 & 538 & 822 & 910 & $\mathrm{P}<0.001$ & 333 & 899 & $\mathrm{P}<0.001$ & 55.8 & $\mathrm{P}<0.02$ \\
\hline Aut. DM prod $(\mathrm{kg} / \mathrm{ha})$ & 3958 & 3903 & 4212 & 4269 & 4036 & $\mathrm{P}<0.109$ & 4368 & 3783 & $\mathrm{P}<0.001$ & 101.7 & NS \\
\hline Total DM prod (kg/ha) & 10154 & 10774 & 11206 & 11943 & 12360 & $\mathrm{P}<0.001$ & 11000 & 11575 & $\mathrm{P}<0.015$ & 232.2 & NS \\
\hline Ground Score & 1.89 & 2.34 & 2.91 & 3.72 & 3.71 & $\mathrm{P}<0.001$ & 2.89 & 2.94 & $\mathrm{P}<0.652$ & 0.12 & NS \\
\hline
\end{tabular}

$\mathrm{SED}=$ Standard error of the difference; $\mathrm{PRG}=$ Perennial ryegrass; Spr.=Spring ; Sum.=Summer; Aut=Autumn; NS=non significant

Inter=Interaction between sward perennial ryegrass content and defoliation method

Conclusions The results of this study show that increasing the PRG proportion of swards significantly increased seasonal and total DM production of grass swards. Results suggest that swards with less than 65\% PRG content are close to the reseeding threshold, particularly if spring DM production is important for the enterprise. Mechanical defoliation of swards compared with AG recorded lower DM yields, with this difference attributed to spring and summer DM production, however overall it appears to be reasonably reflective of AG systems. Visual ground cover scores are a useful indicator of sward production potential. It can also be concluded that sward response to applied nitrogen increases as PRG content increases as all swards received the same level of $\mathrm{N}$ fertiliser.

Acknowledgements The Department of Agriculture and Food Stimulus Fund is acknowledged for its financial support. 